\title{
Expedición por la memoria del conflicto y las iniciativas de paz, desde la escuela Movimiento Expedición Pedagógica Nacional
}

\begin{abstract}
Poetas y mendigos, músicos y profetas, guerreros y malandrines, todas las criaturas de aquella realidad desaforada hemos tenido que pedirle muy poco a la imaginación, porque el desafío mayor para nosotros ha sido la insuficiencia de los recursos convencionales para hacer creíble nuestra vida. Este es, amigos, el nudo de nuestra soledad.

GGM
\end{abstract}

\section{Presentación}

Tal como se expresa en el título, la presente propuesta ${ }^{1}$ toma como eje la necesidad de emprender un nuevo viaje expedicionario por la geografía nacional para reconstruir la memoria del conflicto armado y las iniciativas de paz que se adelantan desde las escuelas.

Desde sus inicios, en 1999, a través de numerosos viajes y rutas por las escuelas de las distintas regiones del país, la Expedición Pedagógica indagó, valoró y exaltó las prácticas de los maestros como productores de saber pedagógico en su relación con la diversidad cultural del país. Después de abordar asuntos como las prácticas pedagógicas, la formación de las maestras y los maestros, sus formas de organización pedagógica, la manera como se adelanta la investigación y circula el conocimiento en la escuela, y la relación de esta con su entorno, el proceso de producción de saber sobre todos ellos ha permitido afirmar la estrecha conexión entre las prácticas pedagógicas y el territorio - lo cual dio lugar a la noción de geopedagogía - y destacar la dimensión ética y política de los maestros y de sus prácticas.

Ese itinerario de la Expedición Pedagógica por la geografía nacional le ha permitido constatar la existencia de una escuela que desarrolla su actividad pedagógica y educativa en medio del exacerbado conflicto armado sobreponiéndose a él y levantando iniciativas de paz para sobrevivir a las dinámicas territoriales de la confrontación bélica.

1 Este documento resulta de las conversaciones adelantadas en los Seminarios Nacionales del Movimiento Expedición Pedagógica durante 2015 (oct-nov) y 2016 (mayo). La escritura recoge aportes de otros equipos expedicionarios y del Equipo de Trabajo Coordinador y fue asumida por los integrantes del Equipo Expedicionario del Caribe, Aroldo Guardiola, Astrid Coronado, Eduardo Lázaro, Manuel Córdoba, Carmen Vega, Gustavo Aragón, María Santa Contreras y Rosalba Núñez. 
La producción expedicionaria sobre las formas de hacer escuela ha permitido visibilizar propuestas y prácticas de paz desde las escuelas, en medio de lo más agudo del conflicto armado, desde las particularidades de cada territorio; también, escuelas que enfrentan con imaginación y firmeza problemáticas asociadas a las profundas desigualdades sociales, como la exclusión, el desplazamiento, las amenazas ambientales, las condiciones de vida y el desconocimiento de las propuestas de vida de los campesinos, los indígenas y los afrodescendientes, entre otros.

Por lo anterior, el Movimiento Expedición Pedagógica, en su decisión de realizar nuevos viajes para el reconocimiento de la diversidad y la riqueza pedagógicas, ha priorizado la movilización, el encuentro, la visibilización de propuestas y de prácticas relacionadas con la construcción de paz desde las escuelas. La experiencia de los viajes, la vitalidad de los equipos regionales y el saber producido constituyen un punto de partida fundamental para su concreción, pero sabemos que contamos hoy con iniciativas y organizaciones, grupos y redes locales, nacionales e internacionales dispuestas a un trabajo conjunto, en un momento que requiere imaginación, voluntad y acciones decididas de todos los colombianos. Contando con todo esto, se acordó en el Seminario Nacional de 2015, con la participación de los equipos regionales, que "la memoria de la violencia y las iniciativas y prácticas de las escuelas en relación con la paz serán un eje en la organización de los nuevos viajes".

Se propone esta Expedición Pedagógica en un momento excepcional de nuestra historia política. La firma de los acuerdos de paz y la orden del cese al fuego definitivo entre el Estado colombiano y las Fuerzas Armadas Revolucionarias de Colombia (FARC) han sido recibidos con entusiasmo por numerosas poblaciones y organizaciones sociales, así como por las universidades, los maestros, su organización sindical, las redes y colectivos pedagógicos, ahora dispuestos a abrir nuevos senderos de reconciliación y de paz.

En la presente propuesta tomamos como base para el análisis dos elementos que marchan aparejados en nuestro devenir histórico: el proceso de construcción del Estado-Nación y los conflictos políticos, sociales y armados que nos Ilevan a referirnos a los enfrentamientos y las guerras civiles que se escenificaron en territorio neogranadino a partir de la cuarta década del siglo Xx. Esa mirada histórica nos permite afirmar que una de las causales o factores que religan los distintos momentos o periodos del conflicto armado es la cultura política predominante en las élites gobernantes, y que presenta como rasgo general la intolerancia, el individualismo, el caciquismo, el pánico a las diferencias y a las controversias democráticas, y el afán desmedido por expulsar al contradictor de los escenarios donde se toman las decisiones de Estado.

Por tales razones, los expedicionarios afirmamos que entrar en contacto y visibilizar las prácticas pedagógicas de los maestros y las maestras y sus iniciativas de paz, lo mismo que abordar el asunto de la memoria de la escuela sobre el conflicto social y armado, es una responsabilidad educativa y pedagógica, un compromiso ético y político con las actuales y las futuras generaciones de estudiantes y maestros de los campos y las ciudades de Colombia. 
Esta responsabilidad, además, debe apoyarse en la determinación de contribuir a la reconciliación y a la construcción de una democracia de participación, social e inclusiva.

Sobre el asunto de la memoria, mencionamos con beneplácito la existencia de importantes trabajos de investigación realizados por universidades y centros de investigación tanto en Colombia como en otros países latinoamericanos, y que, de hecho, son referentes necesarios. En este trabajo específico sobre la memoria del conflicto armado desde la escuela, entendemos la memoria como un ejercicio de reconstrucción de la memoria desde lo vivido por maestros, estudiantes y poblaciones en cada lugar, como "un campo en tensión donde se construyen y refuerzan o retan y transforman jerarquías, desigualdades y exclusiones sociales", como lo plantean en Recordar y narrar el conflicto el Centro Nacional de Memoria Histórica y la University of British Columbia (2013, p. 23), y como un aporte desde la educación a la construcción de la paz en un país que requiere redefinirse desde la paz, no desde la guerra.

En el horizonte de estos nuevos viajes visualizamos la necesidad de concitar las diversas expresiones del Movimiento Pedagógico Nacional a emprender un trabajo conjunto, a partir del reconocimiento de las iniciativas de paz desde las escuelas, como punto de referencia para el diseño de políticas públicas, convencidos, como estamos, de que en el escenario del posacuerdo el país necesita una sustancial reforma educativa, que tenga en cuenta las particularidades de nuestras historias locales y resultado de la participación de los actores sociales y académicos comprometidos con la educación y la nación colombianas.

\section{Territorio, nación y conflicto}

En el nuevo escenario histórico que se presenta en relación con la negociación política y los acuerdos de paz, la Expedición Pedagógica se propone hacer nuevos viajes por las instituciones educativas de las regiones de Colombia, ahora con el propósito de indagar y reflexionar sobre la escuela y el conflicto social y armado que se desarrolla, con variadas intensidades y características, en los territorios, y para detenernos sobre las iniciativas forjadas por los maestros y las maestras desde sus escuelas, en sus prácticas pedagógicas, como trabajadores de la cultura y sujetos de paz. Se busca contribuir, en nuestra condición de expedicionarios, a concitar voluntades y acciones para convocar un movimiento más amplio, que desde la pedagogía impulsa procesos de reconciliación y de paz, y al diseño de una política pública, educativa y pedagógica, sobre la escuela y sus compromisos en el "posacuerdo".

Para concretar estos propósitos, la Expedición Pedagógica por la memoria del conflicto y las iniciativas de paz, desde la escuela parte de reconocer la existencia de un Estado-nación que no acaba de construirse en Colombia, con serias dificultades para liderar la transformación de la sociedad y la integración territorial entre sus diversas regiones. Colombia presenta en su geografía humana un desarrollo social, económico e institucional desiguales. Como nación multiétnica y pluricultural, presenta una marcada disparidad regional. Evidencia de ello es el retraso relativo de regiones como el Caribe colombiano, la Región Pacífica y los Territorios Nacionales, cuyos indicadores de desarrollo están por debajo de la media nacional. De la misma forma, sus pueblos 
originarios (indígenas y afrodescendientes) constituyen los grupos poblacionales más afectados por la pobreza y la exclusión.

Un asunto que merece especial atención es la magnitud de la desigualdad entre el campo y la ciudad, que, acertadamente, se convirtió en uno de los primeros temas durante las negociaciones de paz. Las cifras del Tercer Censo Nacional Agropecuario (DANE), después de 45 años de no hacer un censo sobre el campo colombiano, comprobó con cifras las grandes desigualdades en la tenencia de la tierra: el 69,9\% de las Unidades de Producción Agropecuaria tiene menos de cinco hectáreas y ocupa el 5\% del área censada, mientras que los terrenos de más de 500 hectáreas están en manos del $0,4 \%$ de los propietarios. Pero también reveló que el $11,5 \%$ de los mayores de 15 años es analfabeto y que el $73 \%$ de los menores de 5 años es cuidado por padres o por alguien en la casa o en la parcela, $y$ solo el $16 \%$ asiste a un hogar comunitario o a un centro de desarrollo infantil. En 2014, el $20 \%$ de los niños y los jóvenes entre 5 y 16 años no asistió a ninguna institución educativa, y tampoco lo hizo el 76\% de los jóvenes entre los 17 y los 24. Para agravar la situación, más de la mitad de los jefes de hogar solo tiene educación primaria.

La historiografía y la investigación social dan cuenta de un Estado-nación que surge como resultado de las guerras de independencia libradas a lo largo de la segunda y la tercera décadas del siglo XIX en territorio neogranadino. Los subsiguientes procesos de organización social y articulación de su población al Estado nacional están signados por las guerras civiles o la confrontación armada, que una larga y abarcadora mirada de nuestra historia sociopolítica, aun considerando las continuidades y las rupturas entre un periodo y otro, las conecta con la violencia suscitada más adelante, durante la cuarta y la quinta décadas del siglo Xx, como importantes antecedentes, a su vez, del actual periodo de violencia política.

En esa larga mirada incluimos las reformas hechas a partir de la segunda mitad del siglo XIX, y que contribuyeron con la adquisición de una mayor conciencia nacional y una mayor preocupación por la articulación económica y política del país, a pesar de que, por su calado y su dimensión, no posibilitaron la modernización ni la consolidación del Estadonación. En particular, la estructura de la tenencia de la tierra presenta altos porcentajes de concentración en manos de los hacendados y del Estado, sin que se diseñen políticas de tierra para su democratización.

Durante las décadas subsiguientes se profundiza la búsqueda de la construcción del Estado nacional, enmarcada por las posiciones autonómicas y los conflictos armados que caracterizan la dinámica política territorial, y que van a desembocar en la Convención Nacional, o Asamblea Constituyente de Rionegro (1863) y en la configuración de los Estados Unidos de Colombia, eventos que estuvieron precedidos por un golpe de Estado, la guerra civil de 1861 y el limbo constitucional en el cual desembocó el país. 
No obstante, a estos eventos de búsqueda de la unidad nacional, de solución política de las guerras intestinas, les sucedieron más de 40 rebeliones y levantamientos, cuyas causas se explican por

el reparto burocrático de la tierra, las minas y los bienes según las peculiaridades regionales, con oligarquías que disponían de sus propios ejércitos ante un Estado central que no tenía poder político ni militar, produjo como efecto la descentralización de las guerras que quedaron reducidas al ámbito regional. (Tirado, 1989, p. 174).

Los Estados Unidos de Colombia se disolvieron dos décadas después, debido al triunfo del Partido Nacional de Rafael Núñez en la Guerra de 1885, a la convocatoria a una nueva asamblea nacional constituyente y a la redacción de la Carta Magna de 1886. El gobierno de La Regeneración cimentó de esa manera:

una nación fragmentada y excluyente... los pilares sobre los que se construyen los imaginarios de nuestra nación no presentan una raigambre en la historia del conjunto de los actores sociales. De ello dan fe en este período, como 'lugares de la memoria', el escudo, el himno y las banderas, cuyas imágenes simbolizan elementos de la cultura hispánica, griega y francesa, cuando debieran fundamentarse en nuestra historia y cultura nacionales. Con La Regeneración se prolongó, muy a pesar del himno nacional que escribiera el poeta de El Cabrero, la horrible noche en Colombia. (Guardiola, 2010, p. 223).

Los declarados propósitos políticos de paz y unidad de la Nación de Rafael Núñez, presidente de la República de Colombia y líder de La Regeneración, se constituyeron en una clara muestra del fracaso del proyecto regenerador, a juzgar por los graves acontecimientos que sobrevinieron a finales del siglo XIX, como la cruenta guerra civil denominada La Guerra de los Mil Días y la separación de Panamá. Más adelante, a lo largo de las tres primeras décadas del siglo xx en Colombia, muchos han sido los conflictos sociopolíticos; sin embargo, nuestra historiografía hace especial mención de los conflictos que se suscitan después de la llamada hegemonía conservadora.

Ahora bien, reconocemos en esta síntesis histórica, no solo las continuidades, sino las rupturas, entre los conflictos armados del siglo XIX y los que se presentaron durante la segunda mitad del siglo $x x, y$, especialmente, el actual conflicto armado, empujado por nuevos y diversos factores ${ }^{2}$ que sustentan su existencia y su prolongación en el tiempo. Consideramos, no obstante, que existe un factor de no poca importancia, a nuestro juicio, y el cual no puede soslayarse en el análisis, como lo es el asunto de la cultura política

2 Eduardo Pizarro Leóngomez, uno de los dos relatores de la Comisión Histórica del Conflicto y sus Víctimas, sintetiza como los principales factores que prolongan el actual conflicto: el narcotráfico y la economía de guerra; el papel del secuestro y la extorsión; la precariedad institucional; la provisión privada de la coerción y el fenómeno paramilitar; la inadecuada relación que guardan las armas con las urnas; la inequidad, los derechos de propiedad y la cuestión agraria; los sistemas políticos clientelistas y localistas, y el círculo vicioso de la violencia (Pizarro, 2015). 
predominante en nuestro país, y que actúa como cordón umbilical que enlaza, que religa, los distintos periodos de nuestra violencia política y social.

Esa cultura política, predominante en la élite, presenta como rasgo general la intolerancia, el individualismo, el caciquismo, la búsqueda del enriquecimiento fácil, la negación del otro, el pánico a las diferencias y a las controversias democráticas y el afán desmedido por expulsar al contradictor de los escenarios donde se toman las decisiones de Estado, o bien, la determinación de liquidarlo físicamente mediante el uso de las armas. En Colombia, los sectores dominantes de la sociedad siempre se han mostrado reticentes cuando se trata de la modernización del Estado, y no le ha temblado el pulso para utilizar la violencia como principal recurso cuando ven comprometidos los privilegios de su sistema económico y político. La modernidad, entendida como verdaderos procesos emancipatorios, de secularización del Estado y de democratización de la vida política nacional, es, en gran medida, una asignatura pendiente en Colombia.

\section{El conflicto actual}

El actual conflicto social y armado se expresa en todo el territorio nacional, y presenta como antecedente inmediato las miles de víctimas de la confrontación sectaria librada en la Ilamada época de La Violencia, quienes expresaban en los campos ensangrentados su adhesión a los partidos tradicionales (liberal y conservador), mientras las élites agenciaban un modelo de desarrollo liberal, sectario y excluyente, contrario al espíritu reformador de La Revolución en Marcha y a la integración nacional que ya para entonces se buscaba en otros países latinoamericanos.

Hoy, al igual que en las pasadas centurias de los siglos XIX y XX, la dimensión territorial del conflicto está presente, aunque ahora su territorialización no sea un propósito político en sí mismo, sino una necesidad instrumental al servicio de los objetivos estratégicos de los grupos armados, tales como el control de zonas de importancia social y económica y el control de puntos estratégicos desde el punto de vista militar, como también el control de polos socioeconómicos y de lugares clave para el comercio ilegal de drogas. Esta última estrategia ha sido el propósito principal de los grupos de autodefensa, o paramilitares.

Especial mención hacemos del Frente Nacional, como política de transacción de las élites que les posibilitó el tránsito del gobierno dictatorial, en cabeza de Rojas Pinilla, a un régimen político con ribetes democráticos y la consecución del apaciguamiento de la confrontación política entre las facciones liberales y conservadoras. Se pactan así la consabida alternancia presidencial y la repartición milimétrica en los órganos de representación política y en las altas cortes, y se niega, de esa manera, la participación política de los partidos o los movimientos distintos de los partidos integrantes del Frente Nacional; de hecho, se acude en no pocas ocasiones a la abierta represión o a las medidas propias del estado de sitio para desarticular la protesta popular. 
Fue, precisamente, en los inicios del Frente Nacional cuando surgió el actual movimiento insurgente (las FARC y el Ejército de Liberación Nacional —ELN-), denominados por los violentólogos como movimiento guerrillero de primera generación, y que encuentran en el triunfo de la Revolución Cubana, el 26 de julio de 1959, un importante estímulo para su levantamiento armado. Eventos posteriores, como el derrocamiento militar del gobierno de la Unidad Popular, presidido por Salvador Allende en Chile; el paro cívico nacional realizado en septiembre de 1977 en Colombia; el triunfo de la revolución sandinista en Nicaragua y el cierre de la política de coexistencia pacífica y distensión por parte de la administración norteamericana, en cabeza de Ronald Reagan, traerían consigo un ensanchamiento y una mayor radicalización política del movimiento guerrillero.

Arribamos a la década de 1980 y al crecimiento de la violencia social y política en Colombia. Crecen los índices de homicidios y crímenes violentos "hasta hacer de Colombia el país más violento de América Latina y uno de los más violentos del mundo a finales del siglo XX" (Pizarro, p. 59). Estos homicidios recaen sobre dirigentes locales de los partidos políticos tradicionales y sobre los líderes de los movimientos sociales.

Pero las acciones de exterminio recaen, principalmente, sobre los líderes y los militantes de la Unión Patriótica, movimiento fundado en 1985 como resultado del diálogo de paz entre el gobierno de Belisario Betancur y las FARC. Este movimiento se convirtió en blanco principal de las armas exterminadoras de los grupos de paramilitares, que para entonces hacían su entrada pavorosa en la escena política nacional liquidando físicamente a un partido político de oposición, para vergüenza de nuestra nación y ante los ojos escrutadores de la comunidad internacional. Genocidio político por el que le ha tocado responder al Estado colombiano como principal responsable ante los tribunales internacionales de justicia y de derechos humanos.

Por otra parte, a comienzos de la misma década hace su aparición protagónica el Movimiento 19 de Abril (M-19), movimiento guerrillero de segunda generación, cuyo origen se remonta a los primeros años del decenio de 1970, ligado, según ciertos análisis politológicos, a la lucha electoral por la presidencia de la república, por parte de la Alianza Nacional Popular (ANAPO) y sus demandas de transparencia al gobierno nacional de Carlos Lleras Restrepo, ante el controvertido triunfo electoral de Misael Pastrana Borrero. De igual manera, vienen a engrosar las filas de los movimientos guerrilleros de segunda generación el Movimiento de Autodefensa Obrera (ADO), el Partido Revolucionario de los Trabajadores (PRT) y el Comando Indígena Quintín Lame. El conflicto se exacerba, y en la última década del siglo xx el país es testigo de la agudización de la confrontación armada.

Fue en este contexto de generalización de la guerra, aunque, contradictoriamente, con importantes pactos de paz suscritos por el Estado y los movimientos insurgentes M-19, Ejército Popular de Liberación (EPL), Partido Revolucionario de los Trabajadores (PRT) y Movimiento Armado Quintin Lame (MAQL) (y más tarde, con la Corriente de Renovación Socialista —CRS—), cuando se escenifica en 1991 la Asamblea Nacional Constituyente, 
la cual expide seis meses después de sus deliberaciones la actual Constitución Política, pródiga en el reconocimiento de los derechos de los ciudadanos.

Lo paradójico de esta fase fue esa extraña combinación de promoción del reconocimiento formal de los derechos fundamentales, por un lado, y, la implantación de las políticas de retiro de la intervención del Estado en asuntos cruciales para la convivencia y la equidad, por el otro, así como el impulso de una escueta e incondicional apertura económica. (Montañez, 2004, p 14).

Presenciamos durante la última década del siglo xx y lo que va corrido del siglo XXI una constitución política que incorpora los derechos sociales, en un tiempo que valida el predominio de las reglas del mercado, con su dinámica de negación o subordinación de los derechos fundamentales; todo ello, con las consabidas tensiones que definen la relación de los sectores sociales, en su búsqueda del ejercicio de la soberanía popular, con el Estado y sus políticas públicas que conculcan o limitan las libertades y los derechos de amplias capas de la población colombiana. Al incorporarle el fenómeno del desplazamiento forzado del agro colombiano de millones de campesinos, este cuadro se ensombrece aún más, presenta otros trazos y puntos críticos.

La problemática actual del desplazamiento forzado en Colombia presenta sus primeras y graves manifestaciones durante el periodo de La Violencia (dos millones de personas víctimas de ello) y durante el actual conflicto armado, en las décadas de 1980 y 1990. El fenómeno del desplazamiento se traduce en una crisis humanitaria, como producto de la presencia del paramilitarismo, articulada, a su vez, a la economía del narcotráfico, y debido también al creciente accionar del movimiento guerrillero. El desplazamiento forzado alcanzó la cifra de 5.700 .000 personas en 2014, y de esa manera el país pasó a ocupar el segundo puesto con población en situación de desplazamiento en el mundo, después de la república árabe de Siria. ${ }^{3}$

El problema del desplazamiento afecta a todas las regiones de Colombia, y

al considerar el tamaño y localizaciones de los desplazamientos y sus relaciones con los patrones afianzados de tenencia de tierras y de relaciones políticas pueden advertirse continuidades en el espacio y en el tiempo dentro de los cuales se inscriben los movimientos de población de más largo plazo. (Fajardo, 2000, p 70).

En síntesis, la inequidad, la pobreza, la concentración de la tierra productiva en pocas manos, el masivo desplazamiento de los trabajadores del campo, el desempleo y la movilidad social descendente, así como la criminalidad y la violencia social y urbana crecientes, no solo son causales del deterioro de la calidad de vida, sino que comprometen seriamente la consolidación de la nación y la precaria legitimidad del Estado colombiano.

3 Ver un análisis en detalle sobre el desplazamiento en Colombia en el texto de Consultoría para los Derechos Humanos y el Desplazamiento (CODHES), suscrito por Gabriel Rojas Andrade y Paola Hurtado (2014). 


\section{La escuela, constructora de paz}

El actual conflicto social y armado también ha afectado las universidades y las instituciones educativas en general. La confrontación provocó la muerte o el desplazamiento de los lugares de trabajo de cientos de intelectuales y de maestros y maestras; además, produjo la destrucción física de no pocas instalaciones educativas. Son múltiples las formas de violencia que han padecido nuestros niños, niñas y jóvenes: muertes violentas, violencia sexual, prostitución forzada, desplazamiento, reclutamiento y vinculación forzosa como combatientes a los ejércitos enfrentados. A eso hay que agregar los procesos de desescolarización masiva en momentos de alta conflictividad y el cierre de muchos centros educativos.

Organismos defensores de los derechos de los niños, como la Coalición contra la Vinculación de Niños, Niñas y Jóvenes al Conflicto Armado, denunciaron en su momento otra modalidad violatoria de los derechos de los niños y niñas, por parte de algunas instituciones oficiales, $y$ tan graves como las registradas arriba: poner la actividad educativa de los infantes al servicio de la guerra contrainsurgente.

El Estado se vale de otras formas de involucrar a niños, niñas y jóvenes al conflicto armado, a través de programas cívicos o comunitarios, en donde si bien no participan en acciones militares, desarrollan actividades que los incorporan indirectamente en el conflicto armado. Las consecuencias de esta injerencia, por parte de una de las partes en conflicto, en los medios educativos, son la idealización de las actividades militares y de los combatientes como héroes, la interiorización de valores en torno a la guerra y un grave riesgo para las vidas de los niños y niñas que participan de estas actividades. (Coalición, 2003, p. 7).

Un saldo trágico ha dejado hasta hoy el conflicto armado sobre miles de niños, niñas, maestros y maestras en Colombia, lo cual, de manera oportuna, ha sido documentado y denunciado por organizaciones defensoras de los derechos humanos; en particular, las organizaciones no gubernamentales defensoras de los derechos del niño. Ante tamaña e innegable realidad, a los expedicionarios nos corresponde realizar un trabajo sobre la memoria de la escuela — en cuanto a directivos, niños, madres y padres de familiaasumiendo esta labor como una estrategia útil en la búsqueda de la no repetición de este prolongado capítulo de nuestra historia.

Existe un amplio número de académicos y publicaciones de artículos, tesis y ensayos ocupándose del tema, y granjeándose el honroso título de violentólogos, que reflexionan sobre el conflicto y coadyuvan con la movilización y el fortalecimiento espiritual de los movimientos sociales que a diario trabajan por la construcción de la paz. Esto es importante. Pero lo que no se sabe, lo que no circula en los medios académicos ni de comunicación social, es que en muchas escuelas de las regiones de nuestro país los maestros y las maestras no han estado al margen de la reflexión sobre los asuntos de la guerra y la paz, y desde sus escuelas y sus aulas de clases adelantan importantes prácticas educativas y pedagógicas e iniciativas de paz en conexión directa con sus territorios, lo cual le ha 
permitido a la Expedición Pedagógica identificar y documentar formas de hacer escuela, como la Escuela de la Resistencia, que tiene lugar en Cauca y en otros departamentos del país afectados no solo por el conflicto armado, sino por las fumigaciones aéreas e indiscriminadas con herbicidas para erradicar cultivos ilícitos, agenciadas por el gobierno colombiano dentro del marco del Plan Colombia.

Por lo tanto, la única forma de resistir la situación socio económica que vive el país y el mundo, debe hacerse con lo poco que se tiene que es la tierra y mantener de alguna manera la interacción territorial, donde los campesinos de tierra fría intercambian sus productos, fantasías y espiritualidad con los campesinos de clima medio y cálido a través de los caminos y carreteras que son los hilos conductores de intercambio de vida. (Cauca Pedagógico, 2006).

Otro ejemplo es la Escuela de la Contrapropuesta que, en ciudades como Medellín, entre poblaciones fuertemente azotadas por la pobreza extrema, junto con la presión de las bandas y de los grupos armados al margen de la ley, construye puentes de entendimiento y alternativas culturales frente al robo, la extorsión, el homicidio, el microtráfico y las demás actividades delictivas en las cuales han sido empleados cientos de niños, niñas y jóvenes.

Registramos las aciagas consecuencias del conflicto armado sobre las instituciones escolares asentadas en los territorios, pero enaltecemos la tesonera e intrépida labor de la escuela como constructora de paz. Con la mirada y la reflexión expedicionarias, valoramos el compromiso indelegable de avanzar en la formulación de propuestas de nuevas políticas públicas, sociales y educativas para Colombia. Sin duda, las memorias sobre la escuela y el conflicto armado en Colombia coadyuvarán al enriquecimiento de una nueva pedagogía para la paz.

De la misma forma, consideramos que la reflexión sobre la política pública educativa debe involucrar el debate sobre el tipo de Estado que una nación como la colombiana, multiétnica y pluricultural, está llamada a reconstruir. Como expedicionarios, hemos sido copartícipes de la reflexión sobre la necesidad de diseñar estrategias pedagógicas interculturales para contextos multiculturales como el nuestro. En un nuevo escenario de paz cobra relevancia el análisis crítico sobre el Estado unitario que consagra la constitución política, y que durante los 200 años que llevamos de vida como república independiente se ha revelado como un Estado anacrónico, que actúa de espalda a las dinámicas territoriales y no responde a las características históricas del país ni a sus realidades socioculturales.

\section{Propósitos y rutas expedicionarias}

A partir de lo expuesto, podemos precisar los propósitos de esta Expedición por la memoria del conflicto y las iniciativas de paz desde la escuela, en los siguientes términos: (a) impulsar una movilización social por la paz desde la educación; (b) reconstruir la memoria del conflicto desde la escuela; (c) reconocer y visibilizar las iniciativas de paz desde la escuela; (d) poner en el escenario público los aportes de los viajes a la definición de políticas públicas educativas y sociales, en general; (e) propiciar el intercambio de 
experiencias y el trabajo en red a partir de las iniciativas de paz que se adelantan en cada lugar. Con todo esto, se busca contribuir al fortalecimiento y la ampliación del movimiento pedagógico en Colombia.

Para el trazado de las rutas de estos nuevos viajes, ya hemos iniciado un trabajo de organización y convocatoria en aquellas regiones donde se cuenta con un equipo expedicionario activo, con un importante acumulado de experiencia en la realización de los viajes y la producción de saber. Son estas: Caribe, Medellín, Eje Cafetero, Valle, Cauca y Bogotá.

Se busca, también, como criterio básico, establecer conexiones con las zonas o las subregiones que históricamente se han constituido como escenarios del conflicto armado interno, por ser allí donde la población, en su conjunto, ha sufrido con mayor rigor las consecuencias de la guerra, la ausencia de Estado y el asedio de los actores armados, a lo que se ha sobrepuesto con sus estrategias educativas, pedagógicas y de sobrevivencia. Sin duda, estos escenarios de confrontación armada se reconstruirán con la mirada expedicionaria como el contexto en el cual las generaciones de estudiantes han creado su imaginario de nación y de sociedad inmersa en un conflicto de décadas de existencia.

En tal sentido, registramos las subregiones, las ciudades o las localidades como escenarios geográficos del conflicto en los cuales sería deseable trazar itinerarios en zonas marginales donde ha hecho presencia permanente el conflicto armado, en ciudades como Bogotá, Barranquilla, Medellín, Cali, Tumaco y Buenaventura, al igual que en departamentos como en Guaviare, Caquetá (Florencia, Cartagena del Chairá, San Vicente del Caguán...), Meta, Putumayo, Cauca, Nariño, Antioquia (oriente antioqueño), Tolima, los dos Santanderes (Tibú, San Vicente de Chucurí...) y Córdoba; también, en la Sierra Nevada de Santa Marta (Magdalena, Cesar y La Guajira), el golfo de Urabá, los Montes de María, la Serranía del Perijá, el sur de Bolívar, el suroccidente, el Magdalena Medio, Sumapaz, Montes de Oca (La Guajira) y el golfo de Morrosquillo.

Entre las primeras acciones para realizar por parte de estos equipos está la de convocar a maestros y organizaciones de sus respectivas regiones a construir y definir la propuesta expedicionaria, y ampliar con ello la participación y el movimiento. 


\section{Referencias}

Centro Nacional de Memoria Histórica y University of British Columbia (2013). Recordar y narrar el conflicto. Herramientas para reconstruir memoria histórica. Colombia: Imprenta Nacional.

Coalición contra la Vinculación de Niños, Niñas y Jóvenes al Conflicto Armado (2003). Niñez, escuela y conflicto armado en Colombia.

Comisión Histórica del Conflicto y sus Víctimas (2015). Contribución al entendimiento del conflicto armado en Colombia. Bogotá, D. C., Colombia: Ediciones Desde Abajo.

Departamento Administrativo Nacional de Estadística (DANE) (2015). Censo Nacional Agropecuario, agosto.

De Zubiría, S. (2015). Dimensiones Políticas y Culturales en el conflicto colombiano. En: Comisión Histórica del Conflicto y sus Víctimas. Contribución al entendimiento del conflicto armado en Colombia. Bogotá, D. C., Colombia: Ediciones Desde Abajo.

Expedición Pedagógica Nacional (2001). Preparando el Equipaje. Colombia: Universidad Pedagógica Nacional (No. 2).

Expedición Pedagógica Nacional (2001). Huellas y Registros. Colombia: Universidad Pedagógica Nacional (No. 3).

Expedición Pedagógica Nacional (2003). Caminantes y Caminos, Expedición Pedagógica en Bogotá. Colombia: Universidad Pedagógica Nacional-Fundación Restrepo Barco (No. 4).

Expedición Pedagógica Nacional (2005). Rutas de Vida, Maestros, Escuelas y Pedagogía en el Caribe Colombiano. Colombia: Universidad Pedagógica Nacional (No. 9).

Expedición Pedagógica Nacional (2005). Recreando Rutas y Senderos Pedagógicos, Valle, Cali y Región Norte del Cauca. Colombia: Universidad Pedagógica Nacional- Universidad del Valle (No. 5).

Expedición Pedagógica Nacional (2005). Con los dedos en la filigrana, una mirada crítica a los tejidos metodológicos de la Expedición Pedagógica. Colombia: Universidad Pedagógica Nacional (No. 6).

Expedición Pedagógica Nacional (2006). Recorriendo el Cauca Pedagógico. Colombia: Universidad Pedagógica NacionalUniversidad del Cauca (No. 7).

Expedición Pedagógica Nacional (2006). Pedagogía, Territorio y Cultura. Colombia: Universidad Pedagógica Nacional (No. 8).

Expedición Pedagógica Nacional (2010). Escuelas y Pedagogías Afrocolombianas del Río, el Valle y la Montaña. Memorias de la Ruta Afrocolombiana Sur del Valle, Norte del Cauca de la Expedición Pedagógica Nacional. Cauca: Universidad del Cauca.

Expedición Pedagógica Nacional (2012). Travesía Expedicionaria. Medellín: Expedición Pedagógica de Medellín (No. 10).
Fajardo, D. (2000). Las zonas de Reserva Campesina: ¿Estrategia de desarrollo regional y contra el desplazamiento? En S. Castañeda, D. González, y A. Mores (Compilación y edición). Conversaciones de Paz. Las Claves Territoriales de la Guerra y la Paz. Mandato Ciudadano por la Paz, la Vida y la Libertad. Bogotá: INDEPAZ.

García, M. (1992). De la Uribe a Tlaxcala. Procesos de Paz. Bogotá: CINEP.

González, F. (2014). Poder y Violencia en Colombia. Colección Territorio, Poder y Conflicto. Bogotá: CINEP.

Guardiola, A. (2010). La Regionalización del Caribe Colombiano. Ideas Políticas y Enfoques Económicos. 1981-1999. Santa Marta: Fundaregión.

Montañez, G. (2004). Introducción. En Dimensión Territorial de la guerra y la paz (pp. 13-16). Primera edición. Bogotá: Universidad Nacional de Colombia-Red de Estudios de Espacio y Territorio.

Pizarro, E. (2015). Una lectura múltiple y pluralista de la historia. En Comisión Histórica del Conflicto y sus Víctimas. Contribución al entendimiento del conflicto armado en Colombia. Bogotá, D. C., Colombia: Ediciones Desde Abajo.

Rojas, G. y Hurtado, P. (2014). Grupos posdesmovilización y desplazamiento forzado en Colombia: una aproximación cuantitativa. Bogotá: CODHES.

Tirado, A. (1989). El Estado y la Política en el Siglo XIx. En Nueva Historia de Colombia 2. República. Siglo XIX. Director científico: Jaime Jaramillo Uribe. Bogotá: Planeta.

Universidad Nacional de Colombia, Red de Estudios de Espacio y Territorio (2004). Dimensiones territoriales de la guerra y la paz. Bogotá, D.C. Colombia. 